\title{
SYNTHESIS, COLORFASTNESS EVALUATION AND UTILIZATION OF HUMIC ACID DERIVED DYES / PIGMENT
}

\author{
Saqib Nasir ${ }^{a *}$, Tahira B. Sarfaraz ${ }^{b}$, Khalid M. Khan ${ }^{b}$, Ausaf Aleem $^{c}$, Rasheeda Parveen ${ }^{b}$ \\ $a^{*}$ Pakistan Council of Scientific \& Industrial Research, Ministry of Science \& Technology, Lahore-54000, Pakistan \\ ${ }^{b}$ International Centre for Chemical and Biological Sciences, University of Karachi-75270, Pakistan \\ 'Textile Division, PCSIR Laboratories Complex, Karachi-75280, Pakistan
}

(Received: September 15, 2010 - Accepted: March 18, 2011)

\begin{abstract}
Pakistan coal derived humic acid (HAL) salt was used to synthesize direct azo and acid dyes by coupling reaction with arylamines and its substituted derivatives $\left(\mathrm{R}_{1}-\mathrm{R}_{15}\right)$ for dyeing industry as a reaction intermediates. A variety of color shades ranging from light to deep brown and yellowish were obtained by applying the dyes $\left(\mathrm{D}_{1}-\mathrm{D}_{15}\right)$ to various fabrics. The dyes were noteworthy due to bio-organic in nature, excellent colorfastness to perspiration and washing. The presence of chromophoric groups in a humic acid will explore the utilization of such a natural polymer as potential candidate for the synthesis of dyes and pigments. Colorfastness tests had been studied and significant performance was observed for pure cotton, silk and wool fabrics with certain limitations. The dyed fabrics showed fair to good colorfastness to light and very good to excellent fastness to washing, perspiration, rubbing and seawater. Humic acid and its calcium salt were used to prepare anti-rust pigment using indigenous technique. The humic pigment (HAP) was successfully used for anti-rust purposes in marine paint composition and textile printing application for polyester-cotton fabric. The colorfastness features of printed fabrics were evaluated in comparison with commercially available carbon black pigment (CBP). The computational color data (CIELab) analysis for dyed and printed fabrics were exhibited a good performance of humic derivatives as UV-absorber for value added textile.
\end{abstract}

Keywords: Coal, Humic Acid, Synthesis, Colorfastness, Anti-rust application

\section{INTRODUCTION}

Pakistan coal being lignite in nature can be converted into humic acid (HAL) consisted of condensed aromatic structures substituted by carboxylic, phenolic and heterocyclic groupings linked together through ether linkages [1]. It is a chemically active polymeric compound with a wide agricultural [23], industrial [4-8], environmental [9] and pharmacological [10] applications. It is abundantly found in low rank coal deposits of Pakistan. The potential industrial application of humic acid (HAL) and its derivatives are improving the characteristics of well-drilling fluids, a cement additive, an agent for tanning leather, a pigment in inks, and plasticizer component for polyvinyl chloride. The wide range of humic acid derivatives (HAD) are extensively used as corrosion inhibiting agents in paint and pigment composition.

The chemicals with the above structures are widely used as corrosion inhibiting agents [11]. The humic acid is highly insoluble in organic solvents. It is remarkably thermally stable and shows resistance towards chemical agents to large extent hence best suited for pigment formation. The pigment produced from humic acid salt is brown in color and shows excellent pigment features

A variety of color shades ranging from light to deep brown and yellowish were obtained by applying the various humic direct dyes $\left(D_{1}-D_{15}\right)$. Acid dyes have been found widely applicable for dyeing wool, polyamide fibers and blends of both fibers. The pigment and dye industry is still of elementary nature in Pakistan due to non-availability of basic starting raw material for synthesis and reaction intermediates. The endeavour in the indigenous development of pigment industry become futile due to the utilization of imported expensive raw materials, the final cost of the product exceeds the imported cost forcing the entrepreneur to minimize the operational activities. There exists a wide gap between indigenous production and total demand of pigments / dyes. Pakistan imports $90 \%$ of its pigment from abroad for coating, dyeing and printing purposes. These include dyes and pigments required for undercoat of metallic items, dyeing and printing of cotton, textile, silk, wool, polyester, leather, paper paint and plastic industries.

The diazo groups used for studies are extensively common in organic synthesis and dyeing industry e.g. 1-amino 8-naphthol,3,6-disulfonic acid is one of the most commonly used dye intermediate widely available in the process industry for the synthesis of acid, reactive and azo dyes [12-13].

In present research work we report synthesis of coal derived humic acid (HAL) direct azo and acid dyes with potential capability to use a coloring component of dyeing recipe for various textile fabrics. The great motivation for this research work is to find ways for Pakistani coal utilization and potential applications of such valuable derivatives as dyeing or coloring agents for various textile printing and paint industries.
The synthesis of glossy, corrosion-resistant coating that can be applied directly onto a surface without further undercoat based on coal derived humic acid and its printing applications for cotton fabrics are evaluated.

\section{EXPERIMENTAL PART}

\section{Instrumentation}

UV-visible spectra were obtained on a Nicolet Evolution Model 100 UV/ Visible spectrophotometer (Thermo Electronic Corporation) by dissolving the compounds $\left(\mathrm{D}_{1}-\mathrm{D}_{15}\right)$ in $0.05 \mathrm{~mol} / \mathrm{L}$ sodium hydroxide, dimethylformamide (DMF) and dimethyl sulfoxide (DMSO) The spectra were recorded in a $1 \mathrm{~cm}$ quartz cuvette $(200-700 \mathrm{~nm})$.

\section{General}

The procedure for the synthesis of 4-aminobenzene sulphonic acid humic dye was followed as: coal derived humic acid $(7.5 \mathrm{~g})$ was taken in $5 \%$ sodium hydroxide solution $(150 \mathrm{~mL})$. The solution was stirred magnetically to obtain a clear solution. 4-aminobenzene sulfonic acid $(0.0125 \mathrm{~mol} / \mathrm{g}, 2.15 \mathrm{~mL}$,) was added to $5 \mathrm{~mol} / \mathrm{L} \mathrm{HCl}(5 \mathrm{~mL})$ and cooled to $0{ }^{\circ} \mathrm{C}$. Sodium nitrite $(0.0125$ mole, $1.04 \mathrm{~g}$,) was taken in $20 \mathrm{~mL}$ water, and added to 4 -aminobenzene sulfonic acid in $\mathrm{HCl}$, after addition tested by starch iodide paper for excess of sodium nitrite to determine the end point of diazotization. The clear solution was cooled to $0-5^{\circ} \mathrm{C}$ and then adds dropwise to the coupling solution with vigorous stirring at $0-5{ }^{\circ} \mathrm{C}$; the solution was adjusted to $\mathrm{pH} 7-8$ by the addition of $5 \%$ sodium hydroxide solution. The solution was stirred for 1 hour at $0-5{ }^{\circ} \mathrm{C}$ in an ice water bath. Then mixture was stirred at room temperature for 3-4 hours. The reaction completion point was checked by $\beta$-naphthtol spot test on filter paper. The final solution was dried at $80{ }^{\circ} \mathrm{C}$. Dark brownish solid separated and dried. The residue was crystallized from methanol and dimethylformamide by solvent extraction. 
Table I: Diazo component for synthesis.

\begin{tabular}{|l|l|}
\hline Entry & "Diazo group (mol / g or $\mathrm{mL})$ \\
\hline $\mathrm{R}_{1}$ & 4-aminobenzene sulfonic acid $(0.0125,2.15)$ \\
\hline $\mathrm{R}_{2}$ & 1-amino-8-naphthol-3,6-disulfonic acid $(0.0125,4.0)$ \\
\hline $\mathrm{R}_{3}$ & 4,4-diaminostilbene-2,2-disulfonic acid $(0.005,2.0)$ \\
\hline $\mathrm{R}_{4}$ & 3-aminobenzene sulfonic acid $(0.0125,2.15)$ \\
\hline $\mathrm{R}_{5}$ & 5-amino-1-naphthalene sulfonic acid $(0.0125,2.15)$ \\
\hline $\mathrm{R}_{6}$ & 2-anthranilic acid $(0.0125,1.7)$ \\
\hline $\mathrm{R}_{7}$ & Aniline $(0.0125,1.4)$ \\
\hline $\mathrm{R}_{8}$ & 4-toluidine $(0.0125,1.4)$ \\
\hline $\mathrm{R}_{9}$ & 2-toluidine $(0.0125,1.4)$ \\
\hline $\mathrm{R}_{10}$ & 3-toluidine $(0.0125,1.4)$ \\
\hline $\mathrm{R}_{11}$ & 4-nitroaniline $(0.0125,1.6)$ \\
\hline $\mathrm{R}_{12}$ & 2-nitroaniline $(0.0125,1.6)$ \\
\hline $\mathrm{R}_{13}$ & 4-anisidine $(0.0125,1.5)$ \\
\hline $\mathrm{R}_{14}$ & 3-anisidine $(0.0125,1.5)$ \\
\hline $\mathrm{R}_{15}$ & 2-anisidine $(0.0125,1.5)$ \\
\hline
\end{tabular}

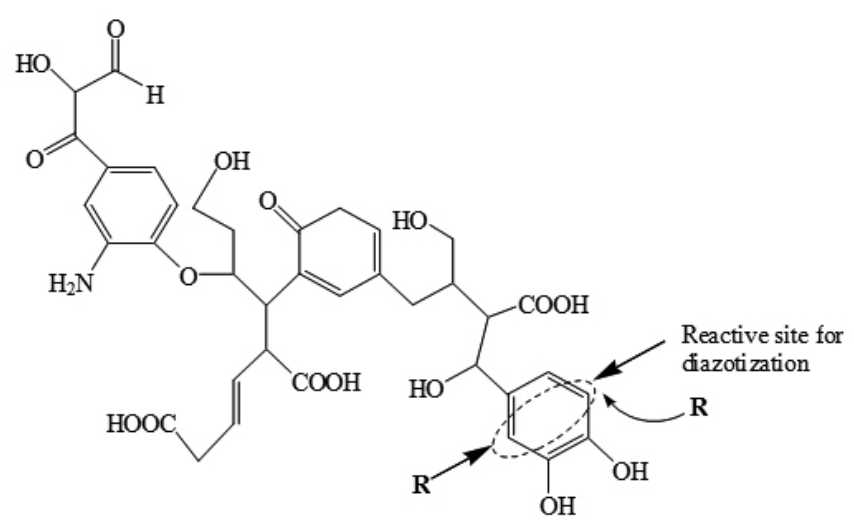

Rl $=4$ aminobenzenesulfonic acid

R2 = 1-amino-8-naphthol-3,6-disulfonic acid

R3 = 4,4-diaminostilbene-2,2-disulfonic acid

R4=3-aminobenzene sulfonic acid

R5 = 5-amino-1-naphthalene sulfonic acid

R6 = 2-anthranilic acid

R $7=$ aniline

R8 = 4-toluidine

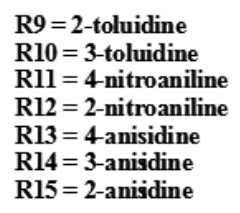

Fig. 1. Proposed interaction of humic acid and diazo group.

\section{Diazotization}

Diazotization was carried out by the usual procedure using sodium nitrite and hydrochloric acid in an ice water bath. The addition of aqueous solution of sodium nitrite $(0.0125 \mathrm{~mol}, 1.04 \mathrm{~g})$ to amine solution $(0.0125 \mathrm{~mol})$ in water except for $\mathrm{R}_{3}$ (4,4-diaminostilbene 2,2-disulfonic acid) $(0.005 \mathrm{~mol}, 2.0 \mathrm{~g})$ was carried out slowly with vigorous stirring. The completion of diazotization was monitored by starch iodide paper.

Coupling

The lignite derived humic acid $(7.5 \mathrm{~g})$ as a coupler was dissolved in 5 $\% \mathrm{NaOH}$ solution $(150 \mathrm{~mL})$. The solution was stirred magnetically to obtain clear solution. The diazo solution was then added dropwise to coupler at room temperature with stirring for 3-4 hour and adjusting the $\mathrm{pH}$ 7-8 with alkaline media $(5 \% \mathrm{NaOH})$. The end point of reaction was monitored by $\beta$-naphthol (spot test on filter paper). The formation of orange color dye was observed shows the presence of excessive diazo component for maximum yield of product. The excessive amount of water was evaporated by vacuum drying at $80^{\circ} \mathrm{C}$ and a clear dried product was obtained.

\section{Dyeing Procedure}

\section{Azo Dyeing}

Dyeing of cotton (garment fabric) was carried out precisely at $80{ }^{\circ} \mathrm{C}$ for 1 hour. The dyeing solution was prepared with a paste of finely powdered dye
$(1 \%)$ in distilled water along with few drops of $1 \%$ aqueous $\mathrm{Na}_{2} \mathrm{CO}_{3}$ with a liquor ratio $20: 1$ for the dyeing bath at $40{ }^{\circ} \mathrm{C}$ and the temperature was raised to $80^{\circ} \mathrm{C}$ for cotton at the rate of $1^{\circ} \mathrm{C} / \mathrm{min}$. The fabric was soaked in cold water before dyeing.

Acid Dyeing

The wool and silk fabrics were soaked in the hot distilled water and squeezed. The direct acid dye $\left(\mathrm{D}_{6}\right)$ was applied at a depth of $4 \%$ with a liquor ratio $20: 1$ along with $2 \%$ (20 g / litre) $\mathrm{Na}_{2} \mathrm{SO}_{4}$ (anhydrous). The $\mathrm{pH}$ of dyeing solution was maintained to 5-6 by addition of $2 \%$ glacial acetic acid.

Colorfastness Tests

The colorfastness to light was assessed in accordance to Australian Standard AS 2001. 4.21 [14]. The colorfastness to washing [15], perspiration [16], rubbing [17] and seawater [18] was carried out in accordance to BS 1006: C 01, BS 1006: E 04, BS 1006: X12 and BS 1006: E 02 respectively.

\section{Synthesis of Humic Acid Pigment}

$1 \mathrm{~kg}$ Humic acid pure, $2 \mathrm{~kg} \mathrm{NaCl}$ (technical grade), $500 \mathrm{~g}$ polyethylene glycol (technical grade) and 2 litre toluene (technical grade) was taken in a ball mill and ground for 48 hours, solvent was removed and pigment washed with water to remove the un-reacted salt. The pigment was dried at $100^{\circ} \mathrm{C}$, finely ground and packed. The final evaluation of pigment "A" in comparison with standard indicated its pigment and anti-rust properties as shown in figure 2 .

$1 \mathrm{~kg}$ finely ground humic acid was put in 2 litre water. $0.5 \mathrm{~mol} / \mathrm{L}$ of $\mathrm{CaCl}_{2}$ in 1 litre water were taken. To mechanically stirred suspension of humic acid, calcium chloride solution in water was added, gradually with heating at $80^{\circ} \mathrm{C}$. After complete addition the mixture was stirred with heating for 4 hours and finally solution was kept overnight. Filtered, washed with excessive water and dried at $100{ }^{\circ} \mathrm{C}$. (Yield: $1250 \mathrm{~g}$ ).

Ca-humate was prepared in crude form with no color intensity and then converted into pigment with physical conditioning or micronization process. $1 \mathrm{~kg} \mathrm{Ca}$-humate (crude), $2 \mathrm{~kg} \mathrm{NaCl}, 500 \mathrm{~g}$ polyethylene glycol, and 2 litre toluene were ground in the ball mill to remove salt. The product was dried at $100^{\circ} \mathrm{C}$. Finally grind the pigment paste for evaluation.

Pigment "B" was evaluated by Pakistan Security Printing Corporation and result showed increase in color intensity as compared to pigment "A" with good anti-rust properties and economically feasible for industrial paint applications.
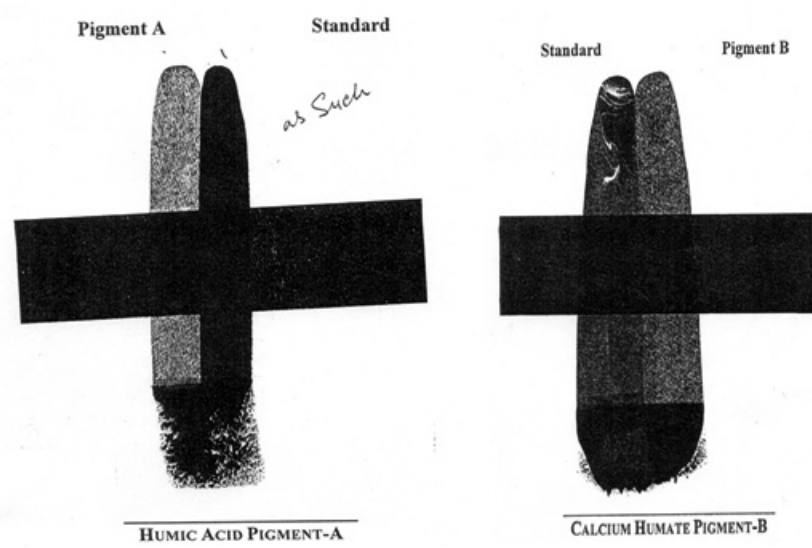

Fig. 2. Anti-rust application of humic pigment.

\section{Humic Pigment - Printing Application}

The textile printing paste was prepared by adding the required amount of humic or carbon black-7 pigment, thickener paste and binder. The viscosity of the resulting printing paste of Humic Acid Pigment (HAP) and Carbon Black-7 Pigment (CBP) was 29,500 cp at 2.5 RPM (11.6 torr) and 151,700 $\mathrm{cp}$ at 2.5 RPM (63.0 torr) respectively. The pigment printing paste used at the shade depth of $4 \%$ for polyester-cotton fabrics and colorfastness / mechanical strength of printed fabric was evaluated. (See Table 7-11)

\section{Printing Procedure}

The printing was carried out on polyester-cotton (PC) fabric by laboratory hand screen-printing methodology. The printed fabric was dried at $120^{\circ} \mathrm{C}$ for 2 min and cured at $155^{\circ} \mathrm{C}$ for $5 \mathrm{~min}$. in a curing machine. The printed PolyesterCotton fabric was shown in figure 3 for comparison of HAP and CBP printed shades. 

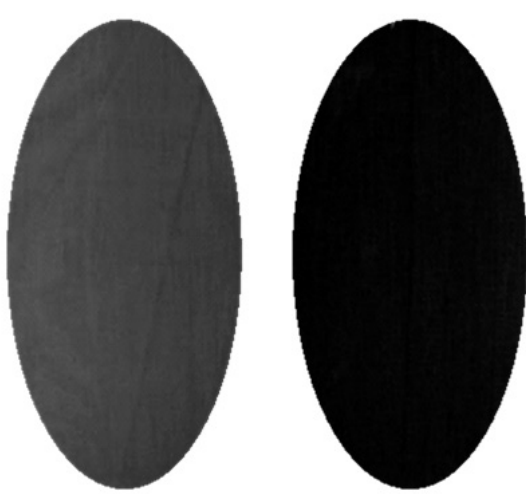

Humic Pigment (HAP) PrintedFabric
Carbon Black-7 Pigment (CBP) PrintedFabric
Fig. 3. Printing application of pigments.

Colorfastness Properties of Printing Pigments

The colorfastness to light, washing, perspiration and crocking was evaluated using standard procedures [14-17].

Pilling Resistance of Textile Fabric: Martindale Tester

The pilling resistance of printed fabrics was evaluated using ASTM D 4970-02.

Colorfastness to Dry-cleaning

The colorfastness to dry-cleaning was evaluated using ISO 105-D 01 procedure.

Abrasion Resistance of Fabric: Martindale Tester

The abrasion resistance of printed fabrics was evaluated in accordance to ISO $12947-2$ procedure.

Computational Data Color - CIELab coordinates

The CIELab coordinates and $\mathrm{K} / \mathrm{S}$ values for printed fabrics before and after curing were evaluated and reported in Table 12.

\section{RESULT AND DISCUSSION}

The humic dyes were applied on cotton, silk and wool fabrics. These dyes give light to deep brown and yellowish shades with good to excellent levelness on the fabric. The present investigation for colorfastness of humic dyes showed a good correlation with reported data in literature [19-20]. The data for UVvisible spectral analysis and colorfastness studies is summarized in Table 2 and 3 .

The data for colorfastness to light is shown in Table 3. The dyed fabric shows a moderate to poor light fastness with rating 1-8. The variation in hues of dyed fabric results from both the nature and position of substituent present on the diazo group. The light fastness is influenced by several factors, such as the chemical and physical state of dye, the dye concentration and nature of fibre.

The data for colorfastness to crocking showed that dyed fabrics possess excellent rubbing in dry with rating 4-5 however rubbing fastness are lower in wet state. The best rubbing fastness (wet) observed for $D_{8}$ and $D_{15}$.

The data for colorfastness to washing showed poor change in shade with moderate to good change in staining on multi-fiber fabric. An excellent washing fastness was obtained with a rating of 4-5 for multi-fiber staining.

The colorfastness to seawater data of dyed fabric showed moderate to excellent change in shade except $\mathrm{D}_{2}, \mathrm{D}_{7}$. The major staining on SDC multifiber for cotton was observed for $\mathrm{D}_{3}$ and $\mathrm{D}_{7}$

Table II: UV-Visible data of humic dyes.

\begin{tabular}{|c|c|c|c|}
\hline \multirow{2}{*}{ Entry } & \multicolumn{3}{|c|}{$\lambda_{(\max )}(\mathbf{n m})$} \\
\cline { 2 - 4 } & $\mathrm{NaOH}$ & $\mathrm{DMF}$ & $\mathrm{DMSO}$ \\
\hline $\mathrm{D}_{1}$ & 328 & 239 & 246 \\
\hline $\mathrm{D}_{2}$ & 227 & 234 & 266 \\
\hline $\mathrm{D}_{3}$ & 330 & 230 & 223 \\
\hline $\mathrm{D}_{4}$ & 207 & 231 & 221 \\
\hline $\mathrm{D}_{5}$ & 283 & 233 & 241 \\
\hline $\mathrm{D}_{6}$ & 230 & 229 & 214 \\
\hline $\mathrm{D}_{7}$ & 208 & 250 & 365 \\
\hline $\mathrm{D}_{8}$ & 231 & 251 & 341 \\
\hline $\mathrm{D}_{9}$ & 213 & 252 & 253 \\
\hline $\mathrm{D}_{10}$ & 205 & 250 & 259 \\
\hline $\mathrm{D}_{11}$ & 207 & 254 & 251 \\
\hline $\mathrm{D}_{12}$ & 328 & 249 & 241 \\
\hline $\mathrm{D}_{13}$ & 257 & 258 & 274 \\
\hline $\mathrm{D}_{14}$ & 215 & 256 & 343 \\
\hline $\mathrm{D}_{15}$ & 219 & 251 & 241 \\
\hline & & & \\
\hline
\end{tabular}

Table III: Colorfastness profile of humic dyes.

\begin{tabular}{|c|c|c|c|c|c|c|c|c|c|}
\hline \multirow[t]{2}{*}{ Entry } & \multirow{2}{*}{$\begin{array}{l}\text { Dyed } \\
\text { Fabric }\end{array}$} & \multirow{2}{*}{ Fabric Shade } & \multirow{2}{*}{$\begin{array}{c}\text { "Light } \\
\text { Fastness" }\end{array}$} & \multicolumn{2}{|c|}{${ }^{* *}$ Crocking Fastness } & \multirow{2}{*}{$\begin{array}{c}{ }^{* *} \text { Seawater } \\
\text { Fastness }\end{array}$} & \multirow{2}{*}{$\begin{array}{c}{ }^{* *} \text { Washing } \\
\text { Fastness }\end{array}$} & \multicolumn{2}{|c|}{${ }^{* *}$ Perspiration Fastness } \\
\hline & & & & Wet & Dry & & & Alkaline & Acidic \\
\hline $\mathrm{D}_{1}$ & Cotton & Brownish & 4 & 3 & 4 & $4-5$ & $1-2$ & $3-4$ & 4 \\
\hline $\mathrm{D}_{2}$ & Cotton & Light brown & 3 & $3-4$ & $4-5$ & 2 & 1 & $1-2$ & 3 \\
\hline $\mathrm{D}_{3}$ & Cotton & Dark brown & 4 & 2 & 5 & 4 & $2-3$ & 4 & 4 \\
\hline $\mathrm{D}_{4}$ & Cotton & Light brown & 3 & $3-4$ & $4-5$ & 3 & 1 & 3 & 3 \\
\hline $\mathrm{D}_{5}$ & Cotton & Brownish & 3 & 2 & 5 & $3-4$ & $1-2$ & $3-4$ & 3 \\
\hline \multirow{2}{*}{$\mathrm{D}_{6}$} & Wool & Brownish & 4 & $3-4$ & 4 & $4-5$ & 4 & $4-5$ & 5 \\
\hline & Silk & Yellowish & $4-5$ & 4 & $4-5$ & 5 & 5 & 5 & 5 \\
\hline $\mathrm{D}_{7}$ & Cotton & Light brown & 4 & 4 & $4-5$ & $2-3$ & $1-2$ & $3-4$ & 5 \\
\hline $\mathrm{D}_{8}$ & Cotton & Light brown & 4 & $4-5$ & 5 & 5 & $2-3$ & $4-5$ & $4-5$ \\
\hline $\mathrm{D}_{9}$ & Cotton & Brownish & 4 & 2 & 5 & 5 & 2 & 5 & 5 \\
\hline $\mathrm{D}_{10}$ & Cotton & Brownish & 5 & 4 & 5 & 5 & 2 & 5 & $4-5$ \\
\hline $\mathrm{D}_{11}$ & Cotton & Brownish & 5 & $2-3$ & 5 & 5 & 2 & $4-5$ & 5 \\
\hline $\mathrm{D}_{12}$ & Cotton & Light brown & 3 & 3 & 5 & 5 & $1-2$ & $4-5$ & 5 \\
\hline $\mathrm{D}_{13}$ & Cotton & Brownish & 4 & 4 & $4-5$ & 5 & 2 & $4-5$ & $4-5$ \\
\hline $\mathrm{D}_{14}$ & Cotton & Light brown & 3 & 3 & 5 & $4-5$ & $1-2$ & 5 & 5 \\
\hline $\mathrm{D}_{15}$ & Cotton & Light brown & 4 & $4-5$ & 5 & 5 & $3-4$ & $4-5$ & 5 \\
\hline
\end{tabular}

"Rating by blue wool scale, ${ }^{* *}$ Rating by grey scale change in shade 
The comparison of changes in redness $\left(\Delta \mathrm{a}^{*}\right)$, blueness $\left(\Delta \mathrm{b}^{*}\right)$, chroma $\left(\Delta \mathrm{c}^{*}\right)$ and color difference $\left(\Delta \mathrm{E}^{*}\right)$ values for dyed fabric samples shows the extent to which each of the different dyeing after soaping is changed in term of color loss from the original dyeing. As seen from the Table 4 the blueness of dyeing for $\mathrm{D}_{6}$ after soaping is significantly higher due to dye migration from inner to outer layer of fibre. In case of control dyeing without auxiliary as observed during this investigation at a temperature of $60-70{ }^{\circ} \mathrm{C}$, the color difference is higher for $\mathrm{D}_{2}$ due to absence of auxiliary, which can modify the dye solubility and hence leads to a lower dye affinity for fibre [21].

Table IV: Computational analysis-CIELab Coordinate.

\begin{tabular}{|c|c|c|c|c|c|c|c|c|}
\hline \multirow{3}{*}{ Entry } & \multicolumn{8}{|c|}{ Datacolor coordinates } \\
\hline & \multicolumn{2}{|c|}{$\mathrm{L}^{*}$} & \multicolumn{2}{|c|}{$\mathrm{A}^{*}$} & \multicolumn{2}{|c|}{$\mathrm{b}^{*}$} & \multicolumn{2}{|c|}{$\mathrm{c}^{*}$} \\
\hline & "B.S. & ${ }^{* *}$ A.S. & B.S. & A.S. & B.S. & A.S. & B.S. & A.S. \\
\hline $\mathrm{D}_{1}$ & 63.10 & $75 . .34$ & 5.99 & 49 & 17.30 & 12.89 & 18.31 & 13.53 \\
\hline $\mathrm{D}_{2}$ & 65.48 & 72.27 & 15.35 & 18.58 & -1.33 & -7.40 & 15.41 & 20.00 \\
\hline $\mathrm{D}_{3}$ & 59.14 & 65.67 & 14.14 & 16.77 & 12.50 & 5.91 & 18.87 & 17.78 \\
\hline $\mathrm{D}_{4}$ & 63.40 & 76.30 & 7.14 & 5.07 & 19.31 & 13.01 & 20.59 & 13.96 \\
\hline $\mathrm{D}_{5}$ & 60.64 & 74.65 & 6.99 & 5.18 & 16.34 & 11.24 & 17.77 & 12.37 \\
\hline \multirow{2}{*}{$\begin{array}{l}\mathrm{D}_{6} \text { (silk) } \\
\mathrm{D}_{6}(\text { wool })\end{array}$} & 60.38 & 69.32 & 11.11 & 9.59 & 30.70 & 31.31 & 32.65 & 32.74 \\
\hline & 56.83 & 60.42 & 7.52 & 6.86 & 26.66 & 26.83 & 27.70 & 27.70 \\
\hline $\mathrm{D}_{7}$ & 54.27 & 70.02 & 7.45 & 6.27 & 18.24 & 15.69 & 19.71 & 16.89 \\
\hline $\mathrm{D}_{8}$ & 57.79 & 73.97 & 7.89 & 6.32 & 19.13 & 15.58 & 20.68 & 16.81 \\
\hline $\mathrm{D}_{9}$ & 59.95 & 76.22 & 7.31 & 5.27 & 19.76 & 15.51 & 21.07 & 16.39 \\
\hline $\mathrm{D}_{10}$ & 58.60 & 72.83 & 7.02 & 5.82 & 18.41 & 15.88 & 19.70 & 16.91 \\
\hline $\mathrm{D}_{11}$ & 59.25 & 70.80 & 8.13 & 6.92 & 20.35 & 17.84 & 21.91 & 19.13 \\
\hline $\mathrm{D}_{12}$ & 58.76 & 73.72 & 7.89 & 6.65 & 17.90 & 15.19 & 19.56 & 16.58 \\
\hline $\mathrm{D}_{13}$ & 58.97 & 72.56 & 8.31 & 6.88 & 18.54 & 15.12 & 20.31 & 16.61 \\
\hline $\mathrm{D}_{14}$ & 63.71 & 77.11 & 7.08 & 6.62 & 18.05 & 13.15 & 19.39 & 14.72 \\
\hline $\mathrm{D}_{15}$ & 60.03 & 73.62 & 7.53 & 6.14 & 17.06 & 13.42 & 18.64 & 14.76 \\
\hline
\end{tabular}

"before soaping **after soaping]

Table V: Computational analysis-Color difference $\left(\Delta \mathrm{E}^{*}\right)$ determination.

\begin{tabular}{|c|c|c|c|c|c|c|c|c|c|}
\hline \multirow{2}{*}{ Entry } & \multicolumn{2}{|c|}{$\Delta \mathrm{L}^{*}$} & \multicolumn{2}{|c|}{$\Delta \mathrm{a}^{*}$} & \multicolumn{2}{|c|}{$\Delta \mathrm{b}^{*}$} & \multicolumn{2}{|c|}{$\Delta \mathrm{E}^{*}$} & \multirow{2}{*}{$\begin{array}{c}\lambda_{(\max )}(\mathrm{nm}) \\
(\text { Fabric Shade) }\end{array}$} \\
\hline & "B.S. & ${ }^{* *}$ A.S. & B.S. & A.S. & B.S. & A.S. & B.S. & A.S. & \\
\hline $\mathrm{D}_{1}$ & 7.05 & 0.94 & -2.7 & -2.57 & -0.85 & -1.96 & 7.59 & 3.36 & 360 \\
\hline $\mathrm{D}_{2}$ & 9.43 & -2.13 & 6.66 & 11.92 & -19.48 & -22.25 & 22.64 & 25.33 & 360 \\
\hline $\mathrm{D}_{3}$ & 3.09 & -8.73 & 5.45 & 10.11 & -5.65 & -8.94 & 8.43 & 16.07 & 360 \\
\hline $\mathrm{D}_{4}$ & 7.35 & 1.98 & -1.55 & -1.59 & 1.16 & -1.84 & 7.60 & 3.13 & 360 \\
\hline $\mathrm{D}_{5}$ & 4.59 & 0.25 & -1.7 & -1.48 & -1.81 & -3.61 & 5.21 & 3.90 & 360 \\
\hline \multirow{2}{*}{$\begin{array}{l}\mathrm{D}_{6} \text { (silk) } \\
\mathrm{D}_{6}(\text { wool })\end{array}$} & 4.33 & 7.08 & 2.42 & 2.93 & 12.55 & 16.46 & 13.49 & 18.1 & 360 \\
\hline & 0.78 & -13.98 & -1.17 & 0.20 & 8.51 & 11.98 & 8.62 & 1.84 & 360 \\
\hline $\mathrm{D}_{7}$ & -1.78 & -4.38 & -1.24 & -0.39 & 0.09 & 0.84 & 2.17 & 4.47 & 360 \\
\hline $\mathrm{D}_{8}$ & 1.74 & -0.43 & -0.8 & -0.34 & 0.98 & 0.73 & 2.15 & 0.91 & 360 \\
\hline $\mathrm{D}_{9}$ & 3.90 & 1.82 & -1.38 & -1.39 & 0.66 & 0.66 & 4.18 & 2.38 & 360 \\
\hline $\mathrm{D}_{10}$ & -1.57 & -1.57 & -0.84 & -0.84 & 1.03 & 1.03 & 2.05 & 2.05 & 360 \\
\hline $\mathrm{D}_{11}$ & -3.60 & -3.6 & 0.26 & 0.26 & 2.99 & 2.99 & 4.68 & 4.68 & 360 \\
\hline $\mathrm{D}_{12}$ & -0.68 & -0.68 & -0.01 & -0.01 & 0.34 & 0.34 & 0.76 & 0.76 & 360 \\
\hline $\mathrm{D}_{13}$ & -1.84 & -1.84 & 0.22 & 0.22 & 0.27 & 0.27 & 1.87 & 1.87 & 360 \\
\hline $\mathrm{D}_{14}$ & 2.71 & 2.71 & -0.04 & -0.04 & -1.70 & -1.70 & 3.19 & 3.19 & 360 \\
\hline $\mathrm{D}_{15}$ & -0.78 & -0.78 & -0.04 & -0.52 & -1.70 & -1.43 & 1.87 & 1.70 & 360 \\
\hline
\end{tabular}

"before soaping ${ }^{* *}$ after soaping 
Table 6 shows the exhaustion and fixation values for all the humic dyes for different fabrics. The higher exhaustion on the cotton fabric was observed for $\mathrm{D}_{7}$ due to relatively open structure of resultant dye hence diffusion of the dye within fabric proceed rapidly under given dyeing conditions. The rate of diffusion for dye molecule into fabric is higher which in turn increases the exhaustion value. The lowest exhaustion value observed for $\mathrm{D}_{8}$ among series of direct azo dyes is probably due to directional influence of para-toluidine. The exhaustion value for direct acid dye $\left(\mathrm{D}_{6}\right)$ for wool fabric is significantly better than silk. The resulting rate of dye fixation is closely related to dye bath temperature, dye reactivity and alkali concentration.

Table VI: Computational analysis-Dyeing parameters.

\begin{tabular}{|c|c|c|c|c|}
\hline \multirow{2}{*}{ Entry } & ${ }^{*}$ B.S. & ${ }^{* *}$ A.S. & $\begin{array}{c}\text { Dye Exhaustion } \\
(\% \mathrm{E})\end{array}$ & $\begin{array}{c}\text { Dye Fixation } \\
(\% \mathrm{~F})\end{array}$ \\
\hline $\mathrm{D}_{1}$ & 2.80 & 1.10 & 3.10 & 1.21 \\
\hline $\mathrm{D}_{2}$ & 3.80 & 2.60 & 9.85 & 6.73 \\
\hline $\mathrm{D}_{3}$ & 3.50 & 1.80 & 11.27 & 5.80 \\
\hline $\mathrm{D}_{4}$ & 3.30 & 1.30 & 10.01 & 3.94 \\
\hline $\mathrm{D}_{5}$ & 3.10 & 1.00 & 25.50 & 8.22 \\
\hline $\mathrm{D}_{6}(\mathrm{silk})$ & 7.90 & 5.00 & 8.12 & 5.13 \\
\hline $\mathrm{D}_{6}($ wool $)$ & 10.00 & 9.00 & 36.70 & 33.03 \\
\hline $\mathrm{D}_{7}$ & 5.00 & 1.52 & 28.54 & 8.70 \\
\hline $\mathrm{D}_{8}$ & 4.20 & 1.77 & 1.40 & 0.59 \\
\hline $\mathrm{D}_{9}$ & 4.00 & 1.15 & 9.10 & 2.61 \\
\hline $\mathrm{D}_{10}$ & 3.70 & 1.35 & 18.60 & 6.78 \\
\hline $\mathrm{D}_{11}$ & 3.70 & 1.55 & 3.30 & 1.38 \\
\hline $\mathrm{D}_{12}$ & 3.70 & 1.20 & 13.20 & 4.28 \\
\hline $\mathrm{D}_{13}$ & 3.75 & 1.30 & 24.44 & 8.47 \\
\hline $\mathrm{D}_{14}$ & 2.80 & 0.85 & 25.15 & 7.63 \\
\hline $\mathrm{D}_{15}$ & 3.20 & 1.10 & 12.80 & 4.40 \\
\hline
\end{tabular}

The crude humic acid has no color intensity. Humic acid converted into pigment form and evaluated from Pakistan Security Printing Corporation shows antirust property with low color intensity (Pigment A). To enhance the color intensity and anti-rust properties the humic pigment was converted to Ca-humate based pigment. The sample was evaluated from Pakistan Security Printing Corporation and results showed that color intensity increased with good anti-rust properties (Pigment B). Its light and chemical fastness properties are satisfactory.

The colorfastness to xenon light data for printing fabrics is shown in Table 7. The observation shows a moderate rating for HAP while its rating for CBP is poor. The colorfastness to washing data is shown in Table 8 and results showed that printing paste based on humic acid pigment (HAP) much better than commercial carbon black-7 pigment (CAP). The HAP showed good rating both for change in shade and staining for multi-fiber. The colorfastness to perspiration data shown in Table 8 shows no prominent difference in the rating of HAP and CBP. Both pigments based printing paste showed moderate to good acidic and alkaline perspiration for polyester-cotton fabric. The colorfastness data to crocking data is shown in Table 9 and clearly shows good to excellent rating for humic acid pigment based printing paste. The CBP based printing paste shows poor crocking features for printed PC fabrics. The pilling resistance data is shown in Table 10. The observation shows a moderate to good rating for HAP however its rating for CBP is poor. The colorfastness to dry-cleaning data is shown in Table 11 and it clearly shows no significant differences between HAP and CBP. Overall both samples are shown moderate to good rating for dry-cleaning.

Table VII: Colorfastness to Xenon light (AATCC Test Method: 16-2003).

\begin{tabular}{|c|c|c|c|}
\hline Entry & \% Shade & Printed Fabric & Rating \\
\hline${ }^{*} \mathrm{HAP}$ & 4 & PC & 5.0 \\
\hline${ }^{* *} \mathrm{CBP}$ & 4 & PC & 3.0 \\
\hline
\end{tabular}

"Humic acid pigment ${ }^{* *}$ Carbon black-7 pigment.

Table VIII: Colorfastness to washing (C 01) and perspiration (E 04).

\begin{tabular}{|c|c|c|c|c|c|c|c|c|c|}
\hline \multirow{2}{*}{ Entry } & \multirow{2}{*}{ \% Shade } & \multirow{2}{*}{ Printed Fabric } & \multirow{2}{*}{$\begin{array}{l}\text { Change } \\
\text { in Shade }\end{array}$} & \multicolumn{6}{|c|}{ Staining in Multi-fiber } \\
\hline & & & & $\mathrm{CA}$ & $\mathrm{CO}$ & $\mathrm{PA}$ & PES & PAC & WO \\
\hline HAP & 4 & Polyester-cotton & $2-3$ & 4 & 3 & $2-3$ & 4 & $3-4$ & 4 \\
\hline \multicolumn{10}{|c|}{ Colorfastness to Acidic Perspiration } \\
\hline HAP & 4 & Polyester-cotton & $4-5$ & $4-5$ & $4-5$ & $4-5$ & $4-5$ & $4-5$ & $4-5$ \\
\hline CBP & 4 & - & 4 & 5 & 5 & 5 & 5 & 5 & 5 \\
\hline HAP & 4 & Polyester-cotton & $3-4$ & $4-5$ & $4-5$ & $4-5$ & $4-5$ & $4-5$ & $4-5$ \\
\hline CBP & 4 & - & $3-4$ & 5 & 5 & 5 & 5 & 5 & 5 \\
\hline
\end{tabular}


Table IX: Colorfastness to crocking (AATCC Test Method 8-2001).

\begin{tabular}{|c|c|c|c|c|c|}
\hline \multirow{2}{*}{ Entry } & \multirow{2}{*}{$\%$ Shade } & \multirow{2}{*}{$\begin{array}{c}\text { Printed } \\
\text { Fabric }\end{array}$} & \multicolumn{2}{|c|}{ Rating } & \multirow{2}{*}{ Remarks } \\
\cline { 4 - 5 } & & Dry & Wet & \\
\hline HAP & 4 & PC & 5 & 3 & Good \\
\hline CBP & 4 & PC & $3-4$ & 1 & Poor \\
\hline
\end{tabular}

Table X: Pilling Resistance: Martindale Tester (ASTM D 4970-02).

\begin{tabular}{|c|c|c|c|c|}
\hline \multirow{2}{*}{ Entry } & \multirow{2}{*}{$\%$ Shade } & \multirow{2}{*}{ Printed Fabric } & \multicolumn{2}{|c|}{ Change in Shade } \\
\cline { 4 - 5 } & & & Stationary & Mobile \\
\hline HAP & 4 & PC & $3-4$ & $4-5$ \\
\hline CBP & 4 & PC & $2-3$ & 3 \\
\hline
\end{tabular}

Table XI: Dry-cleaning (ISO D 01) and Abrasion Resistance (ISO 12947-2).

\begin{tabular}{|c|c|c|c|c|c|}
\hline \multirow{2}{*}{ Entry } & \multirow{2}{*}{$\begin{array}{c}\% \\
\text { Shade }\end{array}$} & \multirow{2}{*}{$\begin{array}{c}\text { Printed } \\
\text { Fabric }\end{array}$} & \multicolumn{2}{|c|}{ Change in Shade } & $\begin{array}{c}\text { Specimen } \\
\text { breakdown }\end{array}$ \\
\cline { 4 - 6 } & & Fabric & $\begin{array}{c}\text { Solution } \\
\text { Staining }\end{array}$ & $\begin{array}{c}\text { No. of } \\
\text { Cycles }\end{array}$ \\
\hline HAP & 4 & PC & $3-4$ & 5 & 13,000 \\
\hline CBP & 4 & PC & 4 & $4-5$ & 13,000 \\
\hline
\end{tabular}

* and ${ }^{* *}$ as indicated in Table 7

The computational analysis data for printed fabrics is presented in Table 12. Color strength value (K/S) [22] of carbon black pigment based printing paste is higher than HAP. The CIELab L*, $\mathrm{a}^{*}, \mathrm{~b}^{*}$ and $\mathrm{c}^{*}$ values are lower for CBP. Furthermore both samples transmitted light at a wavelength $360 \mathrm{~nm}$ and clearly highlight its tendency to absorb harmful UV-radiation in the region of 250-400 nm and rapidly convert it to harmless heat energy. The UV protection properties of such humic compounds are not reported, so, not far hence, a future work plans essentially it focus to find new applications of humic derivatives as UV-absorbers to boost its commercial utilization. Furthermore, synthesis and characterization of such UV-absorbers may give not only a cheaper source for textile dyes but a even it is more economically reliable and environmental friendly due to its biological origin.

Table XII: Computational Data Color-CIELab Coordinates.

\begin{tabular}{|c|c|c|c|c|c|c|c|}
\hline \multirow{2}{*}{ Entry } & \multirow{2}{*}{ Fabric } & $\mathrm{L}^{*}$ & $\mathrm{a}^{*}$ & $\mathrm{~b}^{*}$ & $\mathrm{c}^{*}$ & $\mathrm{~K} / \mathrm{S}$ & \multirow{2}{*}{$\lambda_{\text {(max) }}(\mathrm{nm})$} \\
\hline \multirow{3}{*}{$\mathrm{HAP}$} & Before curing & 58.39 & 4.46 & 14.56 & 15.23 & 3.50 & 360 \\
\cline { 2 - 7 } & After curing & 54.05 & 6.85 & 18.30 & 19.54 & 5.30 & 360 \\
\hline \multirow{3}{*}{$\mathrm{CBP}$} & Before curing & 25.17 & 0.60 & 1.13 & 1.28 & 11.5 & 380 \\
\cline { 2 - 7 } & After curing & 24.13 & 0.48 & 1.12 & 1.22 & 12.30 & 380 \\
\hline \multirow{3}{*}{ HAP } & Original & 59.37 & 5.99 & 16.59 & 17.63 & 3.50 & 360 \\
\cline { 2 - 7 } & Dry Crocked & 60.16 & 5.72 & 16.56 & 17.52 & 3.50 & 360 \\
\cline { 2 - 7 } & Wet Crocked & 56.63 & 5.68 & 16.31 & 17.27 & 4.30 & 360 \\
\hline \multirow{3}{*}{ CBP } & Original & 25.69 & 0.58 & 1.09 & 1.24 & 3.50 & 360 \\
\cline { 2 - 7 } & Dry Crocked & 28.85 & 0.48 & 0.90 & 1.02 & 4.30 & 360 \\
\cline { 2 - 7 } & Wet Crocked & 28.46 & 0.45 & 0.84 & 0.96 & 8.50 & 380 \\
\hline \multirow{2}{*}{ HAP } & Original & 59.17 & 5.25 & 15.80 & 16.65 & 3.60 & 360 \\
\cline { 2 - 7 } & After washing & 66.21 & 4.93 & 14.86 & 15.66 & 2.10 & 360 \\
\hline \multirow{2}{*}{ CBP } & Original & 25.60 & 0.48 & 1.18 & 1.28 & 11.20 & 360 \\
\cline { 2 - 7 } & After washing & 27.19 & 0.40 & 0.77 & 0.87 & 9.20 & 360 \\
\hline \multirow{2}{*}{ HAP } & Original & 59.00 & 5.25 & 15.77 & 16.62 & 3.60 & 360 \\
\cline { 2 - 7 } & After fading & 64.40 & 4.36 & 14.64 & 15.28 & 2.60 & 360 \\
\hline \multirow{2}{*}{ CBP } & Original & 25.55 & 0.50 & 1.18 & 1.28 & 11.00 & 390 \\
\cline { 2 - 7 } & After fading & 25.30 & 0.49 & 1.24 & 1.34 & 11.10 & 390 \\
\hline
\end{tabular}

* and ${ }^{* *}$ as indicated in Table 7

\section{CONCLUSION}

The characteristic colorfastness data collected during investigation for direct humic dyes clearly highlight the potential of lignite derived humic derivatives as dye auxiliary, anti-rust pigment or UV-absorber in coloring industry. However, the application of latest statistical tools with available colorfastness data will help to develop the mathematical correlation and coefficients to further highlight the significance of work. The synthesis of valuable lignite based derivatives will boost up industrial indirect utilization of country low-rank coal reserves as value-aided chemicals. The results of the study indicated that further structural elucidation of synthetic compounds is required using sophisticated thermal degradative and spectroscopic techniques to understand the polymeric nature and reaction mechanism of coupler and resultant direct dye to enhance the commercial applications.

\section{ACKNOWLEDGEMENTS}

The authors acknowledge the Pakistan Security Printing Corporation for providing testing facility. 


\section{REFERENCES}

1. M. Surriaya,, S.M.H. Abdul. Bangladesh J. Sci. and Ind. Res. 34, 363, (1999).

2. M. Ashraf, S. Nasir, T.B. Sarfaraz. Int. J. Biol. Biotech. 2, 737, (2005).

3. M.S. Sarir, M.I. Durrani. J. Agri. Biol. Sci. 1, 16, (2006).

4. F.J. Stevenson, Humus Chemistry: Genesis Composition and Reactions, John Wiley Inter Science, 1994.

5. H. Kleinert. (1996) East German Patent 32730.

6. L. Olle, C. Lorca. AQELC Boletin Tecnico. 34, 343 (1983).

7. C.J. Steelink. J. Chem. Edu. 40, 379 (1963).

8. E.F. Majakova, V.A. Proskirjakov. In: Proc. $4^{\text {th }}$ International Peat Congress, Ontaniemi, Finland, 235-238, (1972).

9. S. Saied, A. Siddique, M. Mumtaz, K. Ali. J. Basic Appl. Sci. 1, 101, (2005).

10. A.J. Simposon, W.L. Kingery, M. Hofmann. Tolouse France, 2, 1109, (2000).

11. S. Horiguchi, M. Nakamura, Y. Sugito. (1978) US Patent 4066462.
12. S. Wang, H.X. Shen. Dyes Pigment. 44, 195 (2000).

13. I.K. Bluss. Dyes Pigment. 41, 149, (1995).

14. Australian Standard Method 2001.4.21: Colorfastness testsDetermination of colorfastness to light using an artificial light source (mercury vapor, tungsten filament, internally phosphor-coated lamp), (2006).

15. BS 1006: C01: Color fastness to washing: Test 1. SDC Standards, pp. C01 06, (1990).

16. BS 1006: E 04: Colorfastness to perspiration, SDC Standards, pp. E 04/1$3,(\mathbf{1 9 9 0 )}$.

17. BS 1006: X 12: Colorfastness to rubbing, SDC Standards, pp. D 12/1-2, (1990).

18. BS 1006: E 02: Color fastness to seawater, SDC Standards, pp. E 02/1-2, (1990).

19. K. Han, W. Kim. J. Korean Chemical Society. 16, 320 (1972).

20. K. Han, W. Kim. J. Korean Chemical Society. 19, 65, (1975).

21. J. Musnickas, V. Rupainyte, R. Treigiene, L. Rageliene. Fibres and Textile in Eastern Europe. 13, 65, (2005).

22. I. Grabchev, T. Konstantinova. Melliand Textilberichte. 2, 125, (1994). 